\title{
Coincidence of Fusion and Concrescence in Mandibular Deciduous Incisors: A Case Report
}

\author{
Dalia E Meisha
}

\begin{abstract}
Aim: The aim of this paper is to report a rare case in which two dental anomalies in primary dentition coexisted-fusion and concrescence in a 4-year-old boy. This highlights the significance of the accurate early diagnosis of these dental anomalies.

Background: Odontogenic anomalies are frequently encountered in dental practice. These anomalies can occur due to abnormalities during the differentiation stage and lead to abnormalities in the hard tissue formation. Dental anomalies in number and form include fusion, gemination, and concrescence.

Case description: Primary dentition with fusion between the right central and lateral primary incisors with increased mesiodistal width. Concrescence between the left central and lateral primary incisors with a groove through the incisal edge. Clinical observation along with radiographic evaluation using intraoral periapical (IOPA) radiographs and orthopantomogram (OPG) were used to arrive at a diagnosis.

Conclusion: Early diagnosis of concrescence will reduce the risk of possible complications associated with any need of extraction later on. Monitoring the patient and long-term follow-up is required to manage the case with coexisting anomalies of true fusion and acquired concrescence.

Clinical significance: A thorough history taking and clinical and radiographic evaluation of fusion and concrescence at an early stage result in an accurate diagnosis. A careful monitoring plan is a key to reduce the risk of possible complications later on.

Keywords: Concrescence, Deciduous, Dental anomaly, Fusion, Primary incisors.

The Journal of Contemporary Dental Practice (2019): 10.5005/jp-journals-10024-2695
\end{abstract}

\section{BACKGROUND}

Fusion is defined as "the dentinal union of two embryologically developing teeth leading to one less tooth than normal in the affected arch." ${ }^{11}$ There are several terms that are used to describe teeth exhibiting fusion, concrescence, or gemination, such as, "double teeth,", 3 "double formations," "joined teeth," "fused teeth," ${ }^{4}$ or "dental twinning." ${ }^{5}$ Radiographic features of fused teeth are "a single pulp chamber along with a single root canal."1,6 Clinically, fused teeth present as an enlarged tooth. While the etiology is still unknown, one of the suggested mechanisms is physical forces causing close proximity between two developing tooth buds and eventually fusion before calcification. ${ }^{7}$ Reported prevalence of fusion ranges from $0.08 \%$ to $1.5 \%$ in deciduous ${ }^{8-12}$ and mixed dentition ${ }^{13-17}$ and $0.19 \%$ in permanent dentition. ${ }^{18}$

In India, Mukhopadhyay and Mitra examined 2,757 nursery children for dental anomalies. The prevalence of double teeth in this study was $0.4 \%$ in deciduous dentition; moreover, half of the patients with dental anomalies in deciduous dentition had also anomalies in the their permanent dentition. ${ }^{10} \mathrm{Wu}$ et al.'s study in China reported a similar observation, where $56 \%$ of children with double teeth in their primary dentition also had problems in their successors. In the case of deciduous dentition, fusion is more common in the mandibular lateral incisors and canines. ${ }^{12}$ Bilateral fusion is less common than unilateral fusion. A study from Spain reported that these anomalies were usually unilateral with no significant differences in the distribution when comparing the left vs the right side, males vs females, or maxilla vs mandible. ${ }^{19}$

Concrescence is defined as "cemental fusion of two roots." 20 Radiographically, this anomaly appears as separate pulp chambers and root canals. This may result either during or after the root formation. The condition is called true/developmental concrescence
Department of Dental Public Health, Faculty of Dentistry, King Abdulaziz University, Jeddah, Kingdom of Saudi Arabia

Corresponding Author: Dalia E Meisha, Department of Dental Public Health, Faculty of Dentistry, King Abdulaziz University, Jeddah, Kingdom of Saudi Arabia, Phone: +966 126403443 ext 23792, email: dmeisha@kau.edu.sa

How to cite this article: Meisha DE. Coincidence of Fusion and Concrescence in Mandibular Deciduous Incisors: A Case Report. J Contemp Dent Pract 2019;20(12):1466-1469.

Source of support: Nil

Conflict of interest: None

if the condition occurs during the formation process, while it is known as the acquired/postinflammatory concrescence if it happens after root formation. ${ }^{1,21}$ In true/developmental concrescence, roots of the affected teeth are in close proximity to each other and are united due to the deposition of a layer of cementum in between them. This may occur due to a previous traumatic injury, crowding with resorption and interdental bone loss, molar distal inclination, space discrepancy, occlusal trauma, or as a response to local infection. ${ }^{2,11,22}$ Concrescence has been reported in maxillary molars and its prevalence does not seem to be influenced by age, gender, or race. ${ }^{1,21,22}$ Zakirulla and Rakesh reported a case with cemental union of the roots of the maxillary primary central and lateral incisor. ${ }^{22}$

These dental anomalies may cause esthetic concerns due to their irregular morphology. In addition, they tend to predispose the patient to caries and periodontal diseases. This is usually complicated with the need for endodontic treatment. Management may involve periodontal, restorative, endodontic, surgical, and/or orthodontic treatment. ${ }^{2,23-27}$ Therefore, the aim of this paper is to 
report a rare case in which fusion and concrescence coexisted and to highlight the significance of an accurate early diagnosis of these dental anomalies.

\section{Case Description}

A 4-year-old boy visited the Department of Pediatric Dentistry with the mother's chief complaint expressed as big teeth in the lower front area. His medical, family, and dental history was noncontributory except for a history of trauma at 16 months of age without any loss of teeth as reported by the mother. Extraoral examination was within normal. Intraoral examination revealed a deciduous dentition stage with an asymmetry in the mandibular arch dentition. There was a large incisor on the right side of the mandibular midline and a double tooth-like appearance on the left side of the mandibular midline. The mesiodistal width of the right mandibular incisor was larger than average. The left mandibular incisor exhibited a linear groove through the incisal edge. The clinical diagnosis was a fused incisor between \#81 and \#82 with an increased mesiodistal width. The fused tooth was vital, caries-free, and of normal shade when compared to the adjacent teeth (Fig. 1). Teeth \#71 and \#72 also exhibited a union, as the dental floss was not able to pass through interproximally. The remaining maxillary and mandibular teeth were within the normal range for shape. All of the affected deciduous incisors were caries-free with no observed functional problems. There were no associated developmental syndromes.

Radiographic examination included requesting an IOPA radiograph and an OPG. The IOPA radiograph showed a complete union of \#81 and \#82 with a wider coronal pulp chamber and single completely developed root canal. Teeth \#71 and \#72 exhibited a union at the cementum without union of dentin, depicting independent pulp chambers and root canals (Fig. 2). Multiple periapical radiographs with different angulations aided in confirming the diagnosis as concrescence tends to defy radiographic detection. The OPG confirmed the presence of all the permanent successors (Fig. 3). Combining the clinical appearance and radiographic examination findings confirmed the diagnosis of fusion between \#81 and \#82 and concrescence between \#71 and \#72.

Since the fusion and concrescence had no adverse impact on occlusion or esthetics and did not cause any discomfort to the young child, remedial treatment for these conditions was not suggested. The patient was placed on a 6-month recall protocol

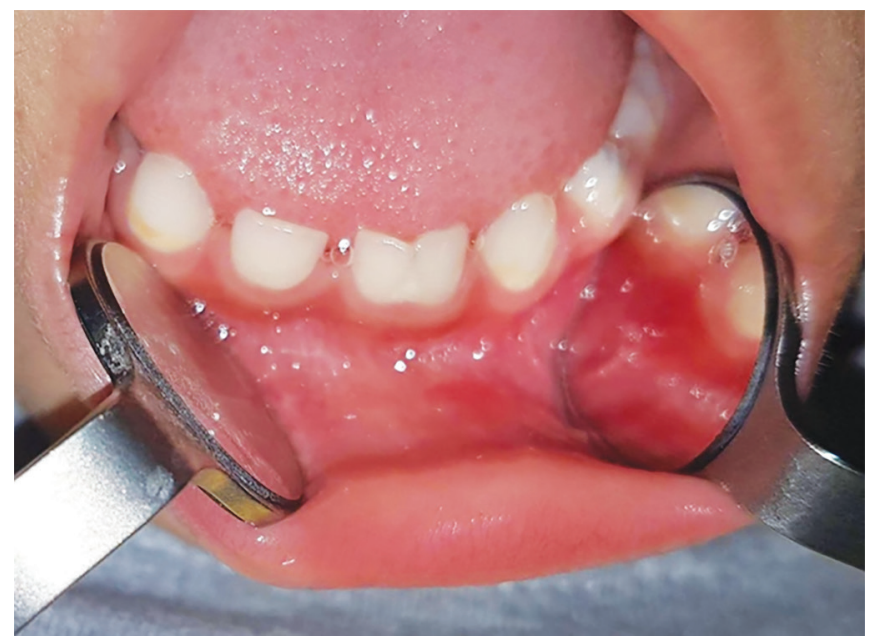

Fig. 1: Intraoral frontal view of mandibular anterior primary teeth for clinical follow-up. The parents were provided with anticipatory guidance for dental caries and informed about the possible consequences of the anomalies in the future.

\section{Discussion}

Despite the significant number of case reports in the literature, the differential diagnosis between fusion and gemination poses a great challenge for dentists. In fusion, a dental deformity is revealed when a tooth count results in a missing tooth (i.e., when the fused teeth are counted as one). A detailed case history with appropriate oral and radiographic examination can lead to an accurate diagnosis of such abnormalities. Based on the formative stage of development, a case can be classified as "true fusion," which is defined as "union by enamel and dentin," or "late fusion," which is defined as "union by dentin and/or cementum." ${ }^{21}$ A late fusion by cementum only is called "concrescence." 20,21 The "true fusion" occurs if the fusion begins before the calcification stage, which shows clinically as a wide crown-as observed in our case in teeth \#81 and \#82 and confirmed by the radiographic imaging. "Late fusion" occurs at an advanced stage of tooth calcification and, therefore, the tooth may exhibit distinct crowns clinically since fusion may be restricted to the root cementum. This describes the concrescence between teeth \#71 and \#72 in this case. Bilateral involvement is rare and only recently reported by Mehta as a case with bilateral fusion of mandibular primary incisors, ${ }^{28}$ whereas Shrivastava et al. reported a single tooth fusion in the primary mandibular incisors. ${ }^{29}$

In the presented case, teeth \#71 and \#72 revealed concrescence. As suggested from the radiographic examination, the concrescence between \#71 and \#72 seems to be of the acquired type. The possible attributed cause for the acquired type of concrescence might be the history of trauma when the child was around 16 months old. The importance of carefully identifying concrescence is to reduce the risk of complications associated with future extraction of the affected teeth. The anomaly may in some cases cause unpleasant esthetic appearance and may increase the susceptibility to dental caries and/or periodontitis. Moreover, the coexistence of fused teeth may compound esthetic concerns, space problems, and occlusal disturbances. In this case, since the anomalies are occurring in the mandibular deciduous incisors, the esthetic problem is not major. As a result, a conservative and preventive approach for these teeth was advocated.

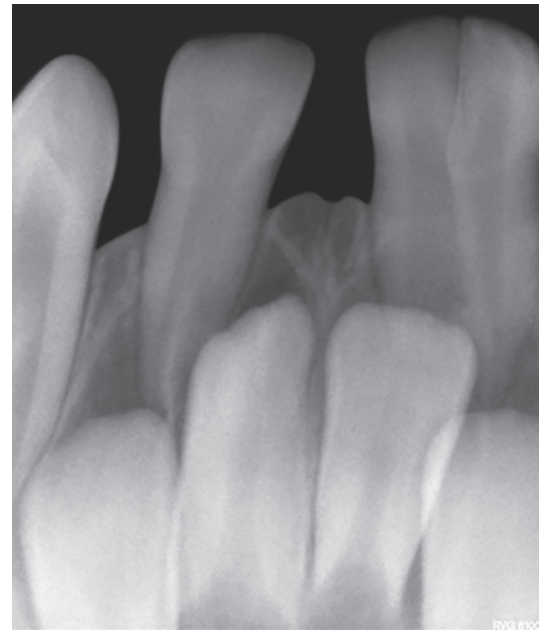

Fig. 2: Intraoral periapical radiograph displaying fusion between \#81 and \#82 and concrescence between \#71 and \#71 


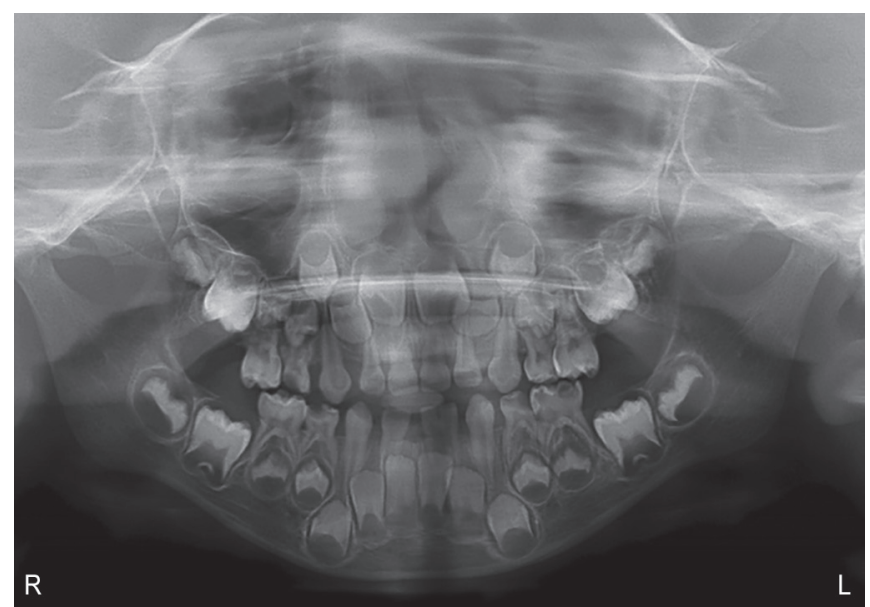

Fig. 3: Orthopantomogram confirming the presence of all the permanent successors

Cases of bilaterally fused anterior teeth in the primary dentition have been reported previously. ${ }^{29}$ However, the fascinating coexistence of both fusion and concrescence in deciduous incisors in the same arch with a history of local trauma makes the present case more extraordinary and worthy of reporting-as only one similar case has been reported in the literature by Singh et al. In that case report, the presence of fusion in maxillary incisors and concrescence in the mandibular incisor region in an 8-year-old child with Down syndrome was reported. ${ }^{30}$ No such medical association was observed in our reported case and the presence of both the fusion and concrescence was in the same dental arch. The fact that the condition affected both mandibular deciduous incisors also makes it a unique case. The history of local trauma occurred at 16 months of age is unlikely to be the cause of fusion as crown formation of mandibular incisors is usually completed by that age.

\section{Conclusion}

A thorough history taking and clinical and radiographic evaluation of fusion and concrescence at an early stage result in accurate diagnosis. A careful monitoring plan is a key to reduce the risk of possible complications in the future. More importantly, early diagnosis of these anomalies is essential part of caries prevention. For example, early diagnosis of concrescence reduces the risk of complications associated with possible need of extraction later on. Monitoring the patient and long-term follow-up is required to manage a case with coexisting anomalies of true fusion and acquired concrescence.

\section{ACKNOWLedgment}

Special thanks to Dr Jehan AlHumaid for her support in the preparation of this case report.

\section{References}

1. Neville BW, Damm DD, Allen CM, et al. Oral and maxillofacial pathology, 4th ed., St. Louis, MO: Saunders Elsevier; 2016.

2. Sivolella S, Bressan E, Mirabal V, et al. Extraoral endodontic treatment, odontotomy and intentional replantation of a double maxillary lateral permanent incisor: case report and 6-year follow-up. Int Endod J 2008;41(6):538-546. DOI: 10.1111/j.1365-2591.2008. 01391.x.
3. Yuen SW, Chan JC, Wei SH. Double primary teeth and their relationship with the permanent successors: a radiographic study of 376 cases. Pediatr Dent 1987;9(1):42-48.

4. Brook AH, Winter GB. Double teeth. A retrospective study of "geminated" and "fused" teeth in children. Br Dent J 1970;129(3): 123-130. DOI: 10.1038/sj.bdj.4802533.

5. Chaudhry SI, Sprawson NJ, Howe L, et al. Dental twinning. Br Dent J 1997;182(5):185-188. DOI: 10.1038/sj.bdj.4809339.

6. Lowell RJ, Solomon AL. Fused teeth. J Am Dent Assoc 1964;68:762. DOI: 10.14219/jada.archive.1964.0159.

7. White $S$, Pharoah MJ. Oral radiology: principles and interpretation, 7th ed., St. Louis, MO: Mosby Elsevier; 2014.

8. Magnússon TE. Hypodontia, hyperodontia, and double formation of primary teeth in Iceland an epidemiological study. Acta Odontol Scand 1984;42(3):137-139. DOI: 10.3109/00016358408993864.

9. Tasa GL, Lukacs JR. The prevalence and expression of primary double teeth in western India. J Dent Child 2001;68(3):196-200.

10. Mukhopadhyay $S$, Mitra $S$. Anomalies in primary dentition: their distribution and correlation with permanent dentition. J Nat Sci Biol Med 2014;5(1):139-143. DOI: 10.4103/0976-9668.127313.

11. Cheng RB, Chen X, Liu SJ. An epidemiological survey on fusion of deciduous teeth of 4286 kindergarten children in Shenyang city. Shanhai Kou Qiang Yi Xue 2003;12(6):424-426.

12. Wu CW, Lin YT, Lin YT. Double primary teeth in children under 17 years old and their correlation with permanent successors. Chang Gung Med J 2010;33(2):188-193.

13. McKibben DR, Brearley LJ. Radiographic determination of the prevalence of selected dental anomalies in children. ASDC J Dent Child 1971;38(6):390-398.

14. Ruprecht A, Batniji S, El-Neweihi E. Double teeth: the incidence of gemination and fusion. J Pedod 1985;9(4):332-337.

15. Salem G. Prevalence of selected dental anomalies in Saudi children from Gizan region. Community Dent Oral Epidemiol 1989;17(3): 162-163. DOI: 10.1111/j.1600-0528.1989.tb00014.x.

16. Bruce $C$, Manning-Cox G, Stanback-Fryer $C$, et al. A radiographic survey of dental anomalies in black pediatric patients. NDA J 1994;45(1):6-13.

17. Bäckman B, Wahlin YB. Variations in number and morphology of permanent teeth in 7-year-old Swedish children. Int J Paediatr Dent 2001;11(1):11-17. DOI: 10.1046/j.1365-263x.2001.00205.x.

18. Hamasha AAH, Al-Khateeb T. Prevalence of fused and geminated teeth in Jordanian adults. Quintessence Int 2004;35(7):556-559.

19. Aguiló L, Gandia JL, Cibrian R, et al. Primary double teeth. A retrospective clinical study of their morphological characteristics and associated anomalies. Int J Paediatr Dent 1999;9(3):175-183. DOI: 10.1046/j.1365-263x.1999.00131.x.

20. American Association of Endodontists. Glossary of Endodontic Terms 9th ed., 2015. Available from: https://www.aae.org/specialty/clinicalresources/glossary-endodontic-terms/ (accessed 4th Sep 2019).

21. Shafer W, Hine M, Levy B. Shafer's textbook of oral pathology, 7th ed., Gurgaon, New Delhi: Elsevier India; 2014.

22. Zakirulla $\mathrm{M}$, Rakesh $\mathrm{N}$. Concrescence in primary dentition: a case report. Int J Clin Dent Sci 2011;2(2):19-21.

23. Sachdeva GS, Malhotra D, Sachdeva LT, et al. Endodontic management of mandibular central incisor fused to a supernumerary tooth associated with a talon cusp: a case report. Int Endod J 2012;45(6):590-596. DOI: 10.1111/j.1365-2591.2012.02029.x.

24. Tsurumachi T, Kuno T. Endodontic and orthodontic treatment of a cross-bite fused maxillary lateral incisor. Int Endod J 2003;36(2): 135-142. DOI: 10.1046/j.1365-2591.2003.00635.x.

25. Karacay S, Guven G, Koymen R. Management of a fused central incisor in association with a macrodont lateral incisor: a case report. Pediatr Dent 2006;28(4):336-340.

26. Rani AK, Metgud S, Yakub SS, et al. Endodontic and esthetic management of maxillary lateral incisor fused to a supernumerary tooth associated with a talon cusp by using spiral computed tomography as a diagnostic aid: a case report. J Endod 2010;36(2): 345-349. DOI: 10.1016/j.joen.2009.07.014. 
27. Stanford ND, Hosni S, Morris T. Orthodontic management of a dental concrescence: a case report. J Orthod 2017;44(3):209-215. DOI: 10.1080/14653125.2017.1357877.

28. Mehta V. Bilateral fusion in mandibular primary anterior teeth: report of a rare case with a brief review of literature. Dent Open J 2017;4(1):10-12.
29. Shrivastava $S$, Tijare $M$, Singh S. Fusion/double teeth. J Indian Acad Oral Med Radiol 2011;23(3):S468-S470. DOI: 10.5005/ jp-journals-10011-1200.

30. Singh A, Bhatia HP, Sharma N. Coexistence of fusion and concrescence of primary teeth: in a child with Down syndrome. Spec Care Dent 2017;3:147-149. DOI: $10.1111 / \mathrm{scd} .12218$. 